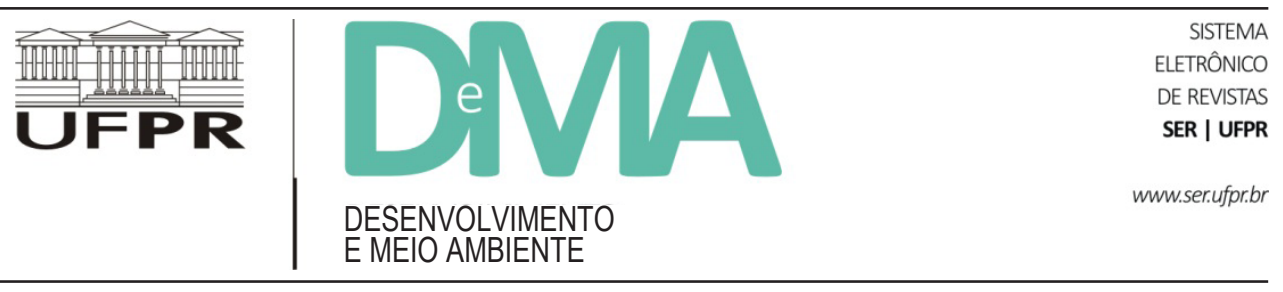

\title{
Recursos genéticos e conhecimentos tradicionais associados: aspectos legislativos sobre sua proteção e acesso
}

\section{Genetic Resources and Associated Traditional Knowledge: Legislative Aspects of Protection and Access}

\author{
Rosemary de Sampaio GODINHO ${ }^{1^{*}}$, Maurício Jorge Pereira da MOTA ${ }^{1}$ \\ ${ }^{1}$ Universidade do Estado do Rio de Janeiro (UERJ), Rio de Janeiro, RJ, Brasil. \\ *E-mail de contato: rosegodinho@globo.com
}

Artigo recebido em 7 de outubro de 2013, versão final aceita em 29 de julho de 2014.

RESUMO No Brasil, o acesso aos recursos genéticos e aos conhecimentos tradicionais a eles associados é regulamentado pela Medida Provisória 2.186-16/01. O caráter provisório da legislação que regula o tema perdura há mais de dez anos, sem data prevista para a edição de uma legislação definitiva. O Conselho de Gestão do Patrimônio Genético (CGEN), criado pela Medida Provisória, era inicialmente o único órgão responsável para análise e emissão de licenças para acesso e coleta de todo o patrimônio natural e seus conhecimentos associados. Essa centralização gerou inúmeros entraves na emissão de tais licenças. O objetivo do presente trabalho é demonstrar os mecanismos utilizados pelo CGEN para oferecer maior celeridade ao acesso desses componentes, contornando a precariedade do instrumento legal disponível. Após a apresentação dos principais personagens envolvidos na matéria, analisaremos os procedimentos adotados pelo CGEN para agilizar os trâmites relacionados às solicitações de acesso ao patrimônio genético e aos conhecimentos tradicionais associados. Para tanto, faremos uso de uma metodologia qualitativa, consistindo no levantamento e na sistematização da documentação disponível sobre o assunto nos portais eletrônicos dos principais órgãos públicos, bem como na revisão bibliográfica realizada a partir de autores que se debruçaram sobre o tema.

Palavras-chave: acesso; conhecimentos tradicionais associados; recursos genéticos.

ABSTRACT The access to the genetic resources and to associated traditional knowledge in Brazil is regulated by the Provisional Law 2.186-16/01. The provisional nature of the legislation has remained for more than ten years, and there is not any prediction for a final definitive law. The Genetic Heritage Management Council (CGEN) created by the Provisional Law was initially the unique body responsible for the analysis and issue of licenses for access and collection of all natural heritage and its associated knowledge. This centralization has generated several difficulties for issuing such licenses. The goal of this work is to show how CGEN handles its skills, to offer more readiness to access its components, avoiding usual law impediments. After introducing the main organisms involved, we will analyze mechanisms applied by CGEN to improve the procedures connected with 
the genetic resources access and the traditional knowledge. In this sense we will adopt a qualifying methodology, surveying the main public organisms web sites, as well as reviewing the bibliography available.

Keywords: access; associated traditional knowledge; genetic resources.

\section{Introdução}

$\mathrm{O}$ acesso à diversidade biológica, cultural e aos recursos genéticos ao longo dos séculos era realizado de forma livre, isto é, sem medidas de controle e fiscalização por parte do poder público. Ao mesmo tempo, como ressaltam Machado e Godinho (2011), até o momento não existiam obrigações internacionais a serem respeitadas pelos Estados em retribuir às comunidades locais e aos povos indígenas benefícios pela utilização dos seus conhecimentos sobre a fauna e a flora apropriados aos setores industriais das biotecnologias.

Somente a partir da realização da Conferência das Nações Unidas para o Meio Ambiente e o Desenvolvimento (RIO-92), quando foi elaborada a Convenção sobre a Diversidade Biológica (CDB), conforme destacado por Tárrega e Pérez (2007), é que se alterou a natureza jurídica da diversidade biológica, passando de res nullius a objeto juridicamente tutelado. Esse tratado internacional propõe inúmeras inovações, que tornam a sua implementação bastante complexa, o que, de acordo com Azevedo (2005), significa um grande desafio às partes signatárias. Essa, nos dizeres de Godinho e Machado (2011), pode ser uma das explicações para a ausência de legislação interna sobre o tema em vários países que ratificaram a CDB.

Um dos grandes desafios propostos pela CDB é a necessidade de se proteger as populações tradicionais, indígenas e não indígenas, bem como os seus conhecimentos tradicionais associados à biodiversidade. $\mathrm{O}$ evento da globalização evidenciou a necessidade de proteção ao meio ambiente como garantia para o futuro da espécie humana e de todo o planeta. Neste sentido, as comunidades tradicionais, povos indígenas e qui- lombolas passaram a ocupar um lugar de destaque no cenário mundial.

O Brasil, na condição de líder entre os dezessete países considerados detentores da maior diversidade biológica do planeta, seguido de Colômbia, Indonésia, China e outros ${ }^{1}$ (Szpilman, 1998), faz parte da minoria que já elaborou uma norma que disciplina o acesso ao patrimônio genético, à proteção e acesso aos conhecimentos tradicionais a ele associados, à repartição de benefícios e o acesso e transferência de tecnologia para sua conservação e utilização.

O marco legal que regulamenta o tema em âmbito federal é a Medida Provisória 2.186-16 de 2001, que criou em seu artigo 10 o Conselho de Gestão do Patrimônio Genético e atribuiu a ele competência para deliberar sobre autorização de acesso e remessa de amostras de patrimônio genético e a conhecimentos tradicionais associados. Entretanto, tal centralização em um só órgão governamental logo se mostrou ineficaz.

Nesse sentido, o objetivo do presente trabalho é demonstrar os mecanismos utilizados pelo CGEN para oferecer maior celeridade ao acesso desses componentes, contornando a precariedade do instrumento legal disponível.

Para tanto, foi realizada uma revisão bibliográfica e análise de textos legislativos e documentos oficiais, inclusive. A revisão bibliográfica foi realizada a partir de uma seleção de textos contidos em livros, capítulos de livros e artigos científicos de autores que têm se debruçado sobre o tema, coletados nas bases de dados Scientific Eletronic Library Online (Scielo) ${ }^{2}$ e Portal de Periódicos da Coordenação de Aperfeiçoamento de Pessoal de Nível Superior (CAPES)3. Também foram realizadas buscas em portais oficiais do governo brasileiro, como o Congresso Nacional, o Conselho Nacional

\footnotetext{
${ }^{1}$ Os outros países são: México, África do Sul, Venezuela, Equador, Peru, Estados Unidos, Papua-Nova Guiné, Índia, Austrália, Malásia, Madagascar, República do Congo e Filipinas.

${ }^{2}$ Disponível em: <http://www.scielo.org/php/index.php>. Acesso em: 04/06/2013.

${ }^{3}$ Disponível em: <http://www.periodicos.capes.gov.br>. Acesso em: 04/06/2013.
} 
de Desenvolvimento Científico e Tecnológico (CNPq), o Instituto Brasileiro de Meio Ambiente e Recursos Naturais Renováveis (IBAMA), o Instituto do Patrimônio Histórico e Artístico Nacional (IPHAN), o Ministério do Meio Ambiente (MMA) e a Presidência da República. Utilizamos os dados disponibilizados nos portais do CNPq, IBAMA, IPHAN e MMA para a elaboração de gráficos apresentados nos resultados da pesquisa.

O resultado de nossa descrição e análise será apresentado em três seções, além desta introdução e da conclusão. Inicialmente, apresentaremos um breve relato sobre a conturbada gênese da legislação analisada. Em seguida, abordaremos a criação e a composição do Conselho de Gestão do Patrimônio Genético (CGEN), órgão criado pela Medida Provisória 2.186-16/01, vinculado ao Ministério do Meio Ambiente (MMA). Após a apresentação dos principais atores envolvidos no tema, analisaremos os mecanismos utilizados pelo CGEN para agilizar os trâmites para solicitação de acesso ao patrimônio genético e aos conhecimentos tradicionais a eles associados. Finalmente, concluímos o artigo afirmando a necessidade de uma legislação definitiva sobre o tema, elaborada pelo poder legislativo e não como vem sendo feito até o momento, onde apenas o poder executivo disciplina o assunto.

\section{Breve histórico sobre o marco regulatório de proteção e acesso aos recursos genéticos $e$ conhecimentos tradicionais a eles associados}

Após a aprovação da Convenção sobre a Diversidade Biológica, ficou evidente a necessidade de uma lei que regulamentasse o acesso aos nossos recursos genéticos e biológicos. Tentando suprir tal lacuna, a então Senadora Marina Silva (PT-AC) apresentou, em 1995, um projeto de lei sobre o tema (PL 306/95), cujo substitutivo, apresentado pelo Senador Osmar Dias (PSDB-PR), foi aprovado por unanimidade na Comissão de Assuntos Sociais do Senado, em 1998 (PL 4.842/98), após ampla discussão e, posteriormente, encaminhado à Câmara dos Deputados. A tramitação de tal projeto de lei contou com a realização de diversas audiências públicas, das quais participaram lideranças populares e indígenas, organizações não governamentais, cientistas e membros do governo.

Enquanto o Projeto de Lei seguia sua tramitação legislativa, em junho de 2000, a organização social Bioamazônia, encarregada pelo governo federal de gerir o Programa Brasileiro de Ecologia Molecular para o Uso Sustentável da Biodiversidade da Amazônia, tentou firmar um contrato de exploração dos recursos genéticos da Amazônia com a empresa multinacional farmacêutica Novartis Pharma AG. Tal contrato, como salienta Bensusan (2003), foi altamente contestado pela sociedade brasileira por inúmeros motivos, dentre os quais as poucas vantagens que o país obteria em comparação com aquelas destinadas à empresa. Por exemplo, em troca da possibilidade de exploração de cerca de 10 mil micro-organismos da Amazônia e da detenção exclusiva das patentes dos eventuais produtos desenvolvidos com base nesses organismos, a Bioamazônia receberia 4 milhões de dólares, em treinamento e transferência de tecnologia. O contrato foi denunciado por conta de suas inúmeras irregularidades e suspenso, entre outros motivos, pelo fato de o Brasil não possuir, na época, legislação específica para garantir a soberania sobre seus próprios recursos genéticos.

A repercussão nacional do caso precipitou a edição de uma Medida Provisória em 29 de junho de 2000, qual

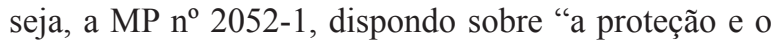
acesso ao conhecimento tradicional associado, a repartição de benefícios e o acesso à tecnologia e à transferência tecnológica para sua conservação e utilização", sobrepondo-se a toda discussão que vinha sendo travada no Congresso Nacional sobre a matéria.

A primeira versão da medida provisória, que foi reeditada sem alterações até abril de 2001, continha vários pontos polêmicos, que foram questionados judicialmente no Supremo Tribunal Federal (STF) por duas Ações Diretas de Inconstitucionalidade (ADI). Por conta da relevância do conteúdo dessas ADIs, as reedições posteriores das Medida Provisória sofreram significativas alterações em seu conteúdo, o que levou o STF a extinguir as ações diretas de inconstitucionalidade por falta de objeto.

Sobre as reedições da medida provisória em análise, Castilho (2003) esclarece que, a partir de maio de 2001 , as reedições passaram a ter o texto alterado, o que 
ocorreu até agosto do mesmo ano. A partir daí, por força da Emenda Constitucional $n^{\circ} 32$, de 12 de setembro de 2001, as medidas provisórias editadas anteriormente à $\mathrm{EC} \mathrm{n}^{\circ} 32$ continuam em vigor até que sejam revogadas explicitamente por outra medida provisória editada posteriormente ou até deliberação definitiva do Congresso Nacional. Assim, o acesso ao patrimônio genético e ao conhecimento tradicional a ele associado, no Brasil, está regulado pela Medida Provisória ${ }^{\circ} 2.186-16$, de 23 de agosto de 2001, em sua $16^{\text {a }}$ reedição, deixando inseguros todos os interessados no tema, diante da vulnerabilidade desse ato normativo com força de lei. Posteriormente, os Decretos no 3.945/2001 e 4.946/2003 vieram regulamentar essa Medida Provisória.

\section{Criação do Conselho de Gestão do Patrimônio Genético}

As determinações introduzidas com a MP 2.18616/2001 no arcabouço legal marcaram uma brusca passagem do modo como se praticava no território nacional o acesso à diversidade biológica e aos conhecimentos tradicionais associados. Uma das mudanças mais significativas foi a criação do Conselho de Gestão do Patrimônio Genético (CGEN), órgão vinculado ao Ministério do Meio Ambiente (MMA), de caráter deliberativo e normativo, composto por representantes de órgãos e entidades exclusivamente da Administração Pública Federal, como estabelece o artigo 10 da Medida Provisória. Entretanto este dispositivo legal não definiu a sua composição, tampouco estabeleceu normas para o seu funcionamento. Com o objetivo de suprir tal lacuna, o governo federal publicou o Decreto 3.945/2001, que foi alterado em 2003 pelo Decreto 4.946. Este último traz um detalhamento maior sobre as autorizações que competem ao CGEN deliberar.

A criação do CGEN, conforme ressalta Bensusan (2003), foi inspirada no projeto de lei original da Senadora Marina Silva, que propunha o estabelecimento de uma Comissão de Recursos Genéticos, representativa dos diversos segmentos da sociedade brasileira, que referendaria as autorizações concedidas por um órgão do governo. Lamentavelmente, a Medida Provisória afastou qualquer possibilidade de participação, transparência e controle social, ao estabelecer um Conselho onde apenas membros do governo federal possuem assento. Além disso, tal determinação desconsiderou o comando constitucional do artigo 23, incisos III, VI e VIII da Constituição Federal de 1988, que estabelece a competência comum à União, Estados e Municípios para exercerem políticas públicas ambientais e suas atribuições administrativas para proteger o meio ambiente. De acordo com Kishi (2004), o disposto no artigo 225, caput, da Carta Magna, que prescreve o dever da coletividade de defender e preservar o meio ambiente, foi desprezado, bem como o princípio da participação popular, uma vez que ainda não existe lei prevendo a participação de representantes da sociedade civil neste conselho. Para atenuar tal falha, a então Ministra do Meio Ambiente Marina Silva, logo após assumir a pasta, determinou que fosse instituída no Conselho a figura do convidado permanente, que são os representantes da sociedade civil. Na prática, as reuniões desse Conselho ocorrem com a participação de 19 membros do governo e apenas 10 representantes da sociedade civil ${ }^{4}$, embora com atuação meramente formal, uma vez que são desprovidos de direito a voto.

\section{Descentralização do Sistema}

Pelo estabelecido na legislação vigente, o CGEN é o órgão responsável pela emissão de autorizações de coleta e acesso à biodiversidade, ao patrimônio genético e aos conhecimentos tradicionais associados. Isso envolve também a avaliação de projetos de pesquisa relacionados ao tema, com finalidade apenas de pesquisa científica, bioprospecção e desenvolvimento tecnológico.

Essa centralização, no entanto, gerou uma enorme burocracia para obter tais autorizações e o acúmulo muito intenso de solicitações no CGEN, que não conseguia atender a demanda em tempo hábil e satisfatório, re-

\footnotetext{
${ }^{4}$ Para a lista completa da composição do CGEN. Disponível em: <http://www.mma.gov.br/patrimonio-genetico/conselho-de-gestao-do-patrimonio-genetico/composicao-do-conselho>. Acesso em: 22/07/2013
} 
sultando na quase total paralisação da pesquisa no país relacionada ao tema, a partir de 2002, o que deflagrou uma série de questionamentos e reivindicações de vários setores da comunidade acadêmica.

A partir de então, o CGEN começou a legislar por meio de Orientações Técnicas e Resoluções, com o objetivo de elucidar alguns pontos obscuros da Medida Provisória e facilitar aos pesquisadores o acesso aos recursos genéticos e aos conhecimentos tradicionais a eles associados. O primeiro questionamento da comunidade acadêmica estava relacionado à definição que a MP trazia de acesso ao patrimônio genético, em seu artigo $7^{\circ}$, inciso IV, que gerava dúvidas sobre o que a legislação considerava acesso e o que seria coleta. Em vista disto, o CGEN esclareceu a questão por meio da Orientação Técnica $n^{\circ} 1 / 2003$, que estabelece que o acesso tem início quando ocorre o isolamento, a identificação ou a utilização da informação de origem genética ou de moléculas e substâncias provenientes do metabolismo dos seres vivos e de extratos obtidos desses organismos. Com isto, a pesquisa taxonômica pura ficou isenta de solicitar autorização ao CGEN, pois não é considerada acesso ao patrimônio genético, bem como o estudo da diversidade genética de populações e a constituição de coleções de DNA.

Mais recentemente, o CGEN estabeleceu algumas exceções, em 2006 e 2007, que não se enquadram sob o conceito de acesso ao patrimônio genético para as finalidades da MP 2.186-16/01 e assim não são necessárias autorizações de acesso para esses casos. A Resolução 21/2006 contemplou quatro exceções, a saber: 1) atividades ou pesquisas que visem avaliar ou elucidar a história evolutiva de uma espécie ou de grupo taxonômico, as relações dos seres vivos entre si ou com o meio ambiente, ou a diversidade genética de populações; 2) testes de filiação, técnicas de sexagem e análises de cariótipo ou de DNA que visem à identificação de uma espécie ou espécime; 3) pesquisas epidemiológicas visando à identificação de agentes etiológicos de doenças, assim como a medição da concentração de substâncias conhecidas cujas quantidades nos organismos indiquem doenças ou estado fisiológico; 4) pesquisas que visem à formação de coleções de DNA, tecidos, germoplasma, sangue ou soro. Por sua vez, a Resolução 29/2007 isentou de autorização específica a elaboração de óleos fixos, óleos essenciais e de extratos quando esses resultarem de isolamento, extração ou purificação, nos quais as características do produto final sejam substancialmente equivalentes à da matéria-prima original.

$\mathrm{Na}$ tentativa de dar maior celeridade ao processo de emissão de autorizações, a partir de 2003 o CGEN começou a ganhar braços auxiliares para descentralizar os pedidos. Primeiro, foi o Instituto Brasileiro do Meio Ambiente e dos Recursos Naturais Renováveis (IBAMA), também vinculado ao MMA, que foi credenciado para autorizar acesso e a remessa de amostras de componentes do patrimônio genético apenas para fins de pesquisa científica, por intermédio da deliberação $n^{\circ} 40 / 2003$ do CGEN. Em seguida, o Instituto Chico Mendes de Conservação da Biodiversidade (ICMBio), em 2007, começou a analisar solicitações de coleta por meio do Sistema de Autorização e Informação em Biodiversidade (SISBIO), instituído pela Instrução Normativa $n^{\circ} 154$ de 2007 do IBAMA, que emite apenas autorização para captura, coleta, marcação, manutenção em cativeiro de espécimes da fauna silvestre e pesquisa em Unidades de Conservação Federais. Entretanto, vale ressaltar que, quando o acesso ao conhecimento tradicional associado ocorrer nessas Unidades de Conservação, o pesquisador deverá registrar a sua solicitação no SISBIO a fim de obter autorização para a realização de pesquisa.

O IBAMA disponibiliza em sua página apenas as autorizações emitidas a partir de $2008^{5}$. A Figura 1 demonstra que no período entre 2008 e agosto de 2013 foram emitidas 104 autorizações, sendo 3 em 2008, 39 em 2009, 16 em 2010, 11 em 2011, 28 em 2012 e 7 em 2013.

Em 2009, por intermédio da deliberação n ${ }^{\circ} 246$, o CGEN credenciou o Conselho Nacional de Desenvolvimento Científico e Tecnológico (CNPq), órgão vinculado ao Ministério da Ciência, Tecnologia e Inovação (MCTI), para autorizar instituições nacionais, públicas ou privadas, que exerçam atividades de pesquisa e desenvolvimento nas áreas biológicas e afins a acessar

\footnotetext{
${ }^{5}$ Dados Disponíveis em: <http://www.ibama.gov.br/servicos/acesso-e-remessa-ao-patrimonio-genetico>. Acesso em: 09/08/2013.
} 


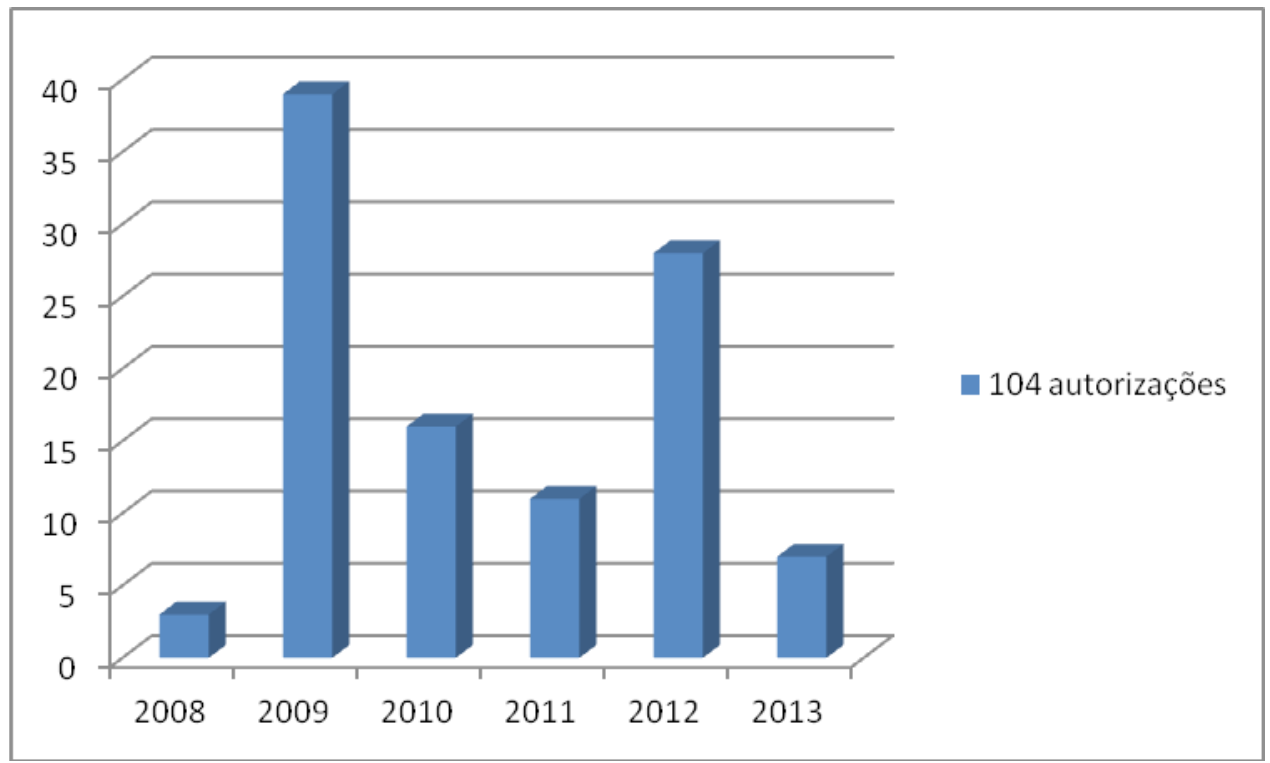

FIGURA 1 - Autorizações concedidas pelo Instituto Brasileiro do Meio Ambiente e dos Recursos Naturais Renováveis - IBAMA - a partir de 2008.

FONTE: Godinho \& Mota (2013), a partir dos dados disponibilizados no portal do IBAMA 6 .

amostra de componente do patrimônio genético para fins de pesquisa científica, e remeter amostra de componente do patrimônio genético a instituição sediada no exterior, para fins de pesquisa científica. Pelo estabelecido nesta mesma deliberação, o CNPq se obriga a encaminhar ao CGEN as solicitações de autorização de acesso e remessa de patrimônio genético para fins de bioprospecção e desenvolvimento tecnológico e as que envolverem acesso a conhecimento tradicional associado. Vale destacar que o credenciamento do CNPq não prejudicaria o credenciamento do IBAMA. O sistema do CNPq não permite a concessão de autorizações especiais de acesso, atende apenas às solicitações de autorização para projetos individuais. As autorizações especiais só podem ser concedidas pelo IBAMA.

Já no ano seguinte, por meio da deliberação 268/2010, o CGEN ampliou o credenciamento do CNPq, incluindo em sua competência autorizações para o acesso e remessa de amostras de componente do patrimônio genético também para fins de bioprospecção e desenvolvimento tecnológico. Por intermédio da resolução normativa $n^{\circ} 3$ de 2012, o CNPq estabeleceu os critérios para o cadastramento das instituições interessadas. $\mathrm{O}$ novo sistema do CNPq, de acordo com Carvalho (2012, p. 2), integra a plataforma Carlos Chagas. Com isso, as informações devem ser fornecidas exclusivamente por meio eletrônico, dispensando o uso de documentos impressos.

A Figura 2 demonstra que, no período entre 2010 e agosto de 2013, o $\mathrm{CNPq}^{7}$ concedeu 154 autorizações de acesso e remessa de amostra de componente do patrimônio genético, o que confirma um processo mais célere que o do IBAMA.

Apesar de mais célere, o número de autorizações concedidas pelo CNPq ainda se mostra distante do satisfatório para um país biodiverso como o nosso.

\footnotetext{
${ }^{6}$ Disponível em: <http://www.ibama.gov.br/servicos/acesso-e-remessa-ao-patrimonio-genetico>. Acesso em: 09/08/2013.

${ }^{7}$ Informação obtida no site do Conselho Nacional de Desenvolvimento Científico e Tecnológico. Disponível em: <http://memoria.cnpq.br/ patrimonio_gen/docs/autorizacoes_concedidas.pdf>. Acesso em: 19/07/2013.
} 


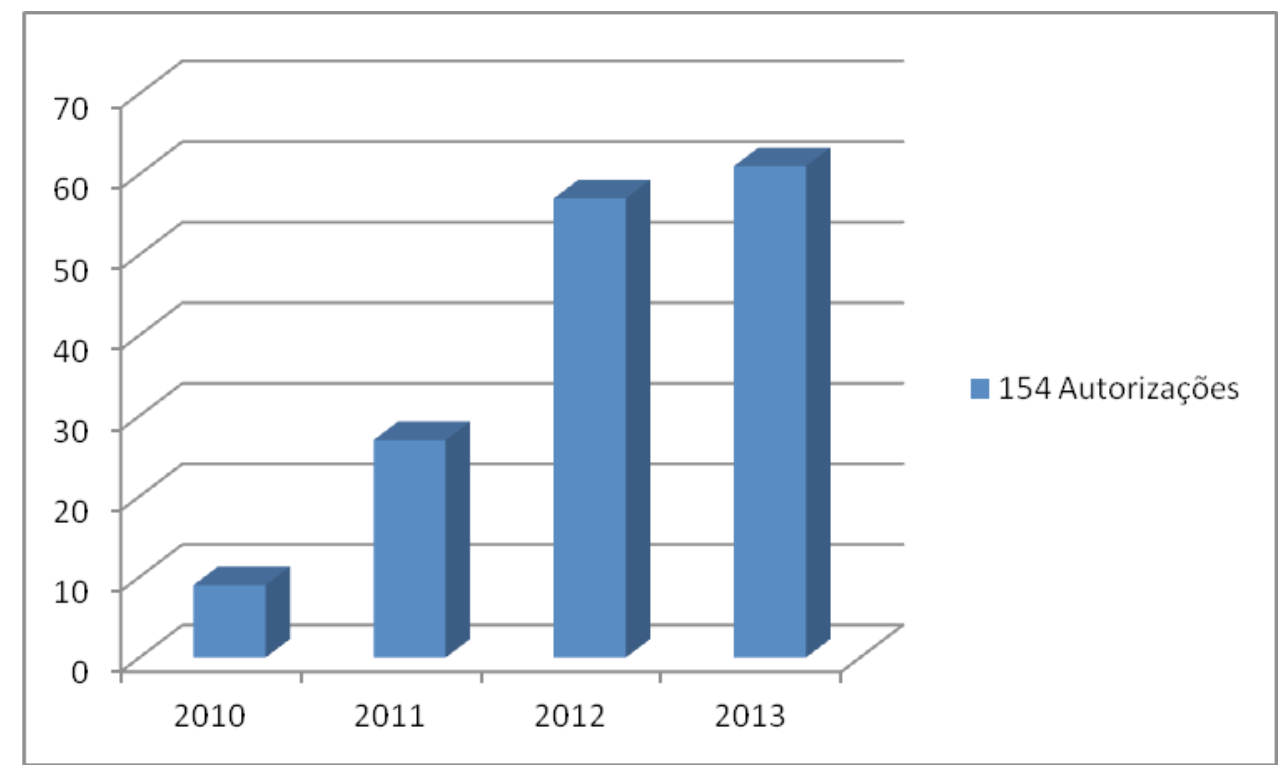

FIGURA 2 - Autorizações concedidas pelo Conselho Nacional de Desenvolvimento Científico e Tecnológico (CNPq) a partir de 2010.

FONTE: Godinho \& Mota (2013), a partir dos dados disponibilizados no portal do CNPq ${ }^{8}$.

Em setembro de 2011, de acordo com Vasconcellos (2012, p. 1), foi aprovado por meio da deliberação $n^{\circ} 279$ do CGEN o credenciamento do Instituto do Patrimônio Histórico e Artístico Nacional (IPHAN), vinculado ao Ministério da Cultura, para emitir autorizações a pesquisas científicas relacionadas ao acesso dos conhecimentos de povos tradicionais sobre o patrimônio genético. Com este credenciamento, o CGEN demonstra claramente considerar o conhecimento tradicional como patrimônio cultural, revelando assim a sua interpretação do artigo 216 da Constituição Federal.

A Figura 3 mostra que o IPHAN emitiu 19 autorizações nesses dois anos, sendo 13 em 2012 e 6 em $2013^{9}$.

Apesar do credenciamento dessas instituições, o CGEN $^{10}$, conforme demonstrado na Figura 4, emitiu 147 autorizações no período entre 2003 e agosto de 2013, sendo 9 em 2003, 4 em 2004, 10 em 2005, 19 em 2006,

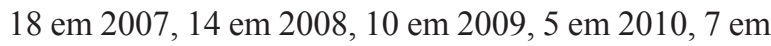
2011, $50 \mathrm{em} 2012$ e apenas $1 \mathrm{em} 2013$.

Entre todas as autorizações do CGEN apenas dez empresas privadas foram contempladas. São elas: Quest International do Brasil Indústria e Comércio Ltda., Extracta Moléculas Naturais S.A., Ciclo Farma Indústria Química Ltda., APIS Flora Industrial e Comercial Ltda., Cristalia Produtos Químicos Farmacêuticos Ltda., Cognis do Brasil Ltda., Lychnoflora Pesquisa e Desenvolvimento de Produtos Ltda. (todas essas com apenas uma autorização); Croda do Brasil, com 3 autorizações; Solabia Biotecnologia Ltda., com 10 autorizações e Na-

\footnotetext{
${ }^{8}$ Disponível em: <http://memoria.cnpq.br/patrimonio.gen/docs/autorizacoes_concedidas.pdf $>$. Acesso em: 09/08/2013.

${ }^{9}$ Dados disponíveis em: <http://portal.iphan.gov.br/portal/montarDetalheConteudo.do?id=16555\&sigla=Institucional\&retorno=detalheInstitu cional>. Acesso em: 09/08/2013.

${ }^{10}$ Informação obtida no site do Ministério do Meio Ambiente. Disponível em: <http://www.mma.gov.br/patrimonio-genetico/conselho-de-gestao-do-patrimonio-genetico/processos>. Acesso em: 19/07/2013.
} 


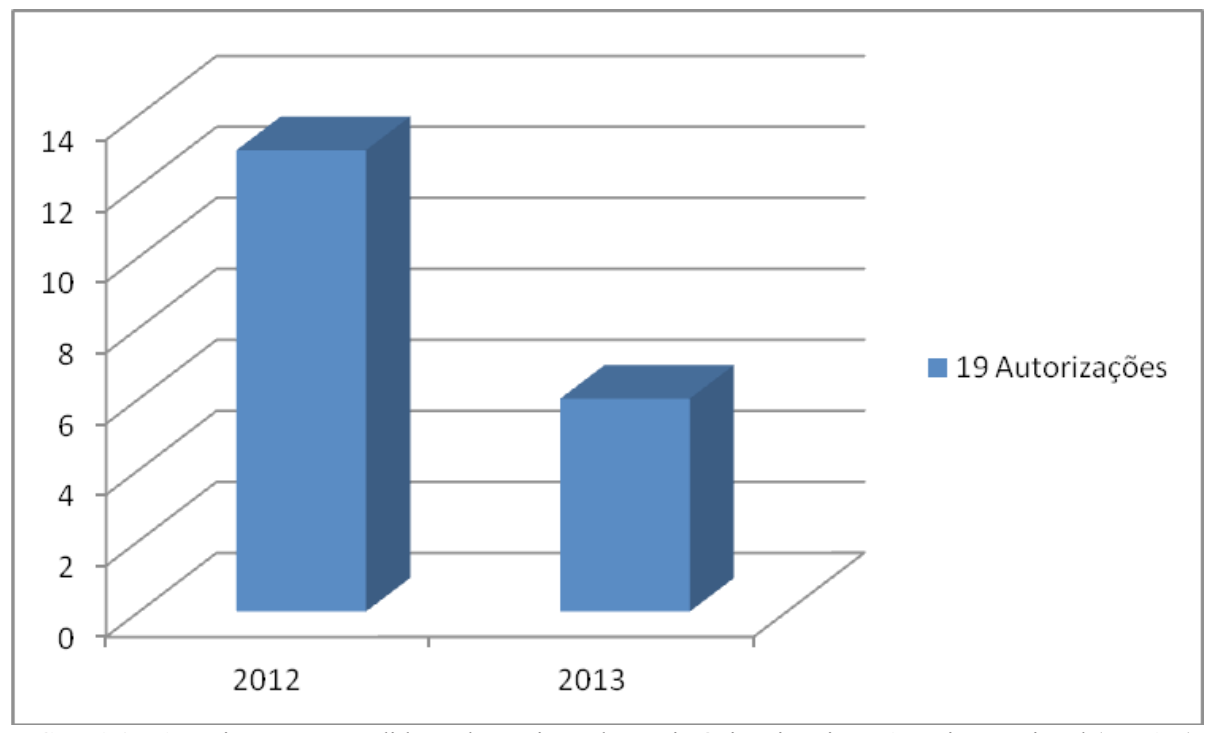

FIGURA 3 - Autorizações concedidas pelo Instituto do Patrimônio Histórico e Artístico Nacional (IPHAN), a partir de 2012.

FONTE: Godinho \& Mota (2013), a partir dos dados disponibilizados no portal do IPHAN ${ }^{11}$.

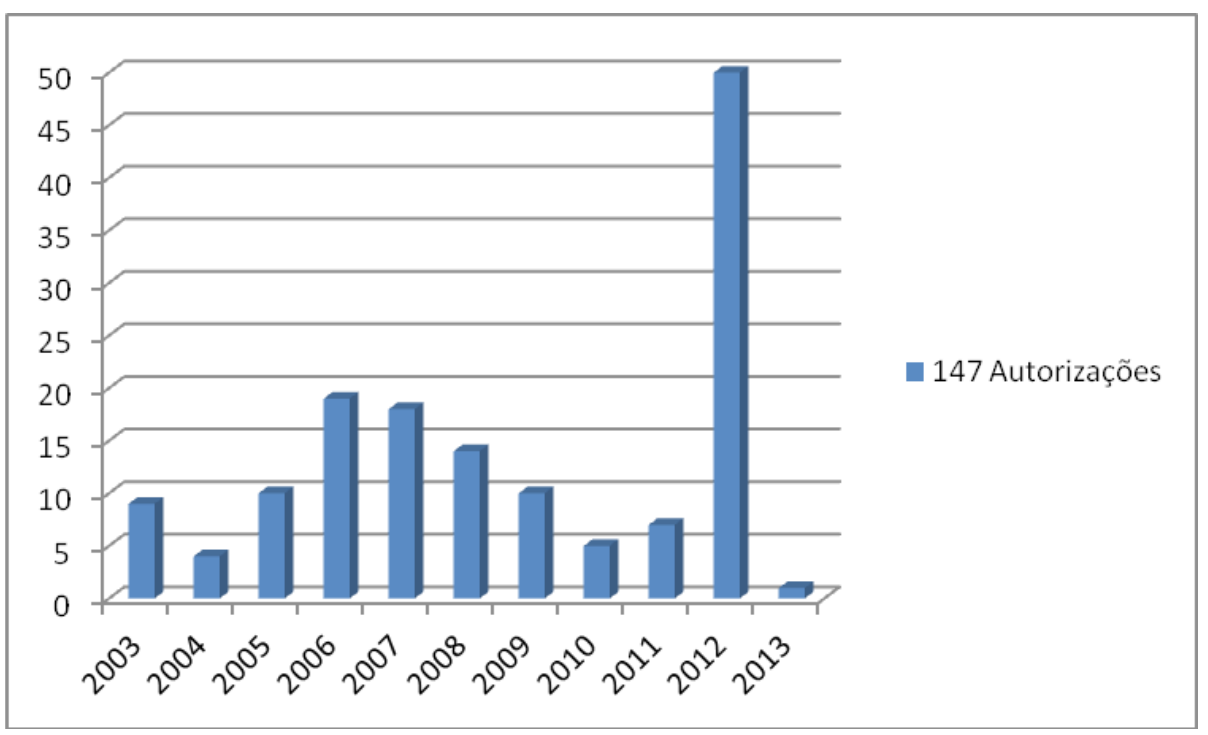

FIGURA 4 - Total de autorizações emitidas pelo Conselho de Gestão do Patrimônio Genético (CGEN), a partir de 2002.

FONTE: Godinho \& Mota (2013), a partir dos dados disponibilizados pelo CGEN ${ }^{12}$.

${ }^{11}$ Disponível em: < http://portal.iphan.gov.br/portal/montarDetalheConteudo.do?id=16555\&sigla=Institucional\&retorno=detalheinstitucional $>$. Acesso em: 09/08/2013.

${ }^{12}$ Disponível em: <http://www.mma.gov.br/patrimonio-genetico/conselho-de-gestao-do-patrimonio-genetico/processos >. Acesso em: 09/08/2013. 
tura Inovação e Tecnologia de Produtos Ltda. ${ }^{13}$, com 36 autorizações, sendo esta última a única que conseguiu autorização para acesso a conhecimento tradicional associado à biodiversidade.

Baseado nos dados apresentados nas Figuras 1, 2, 3 e 4, foi possível avaliar a relação entre o número de autorizações para acesso a patrimônio genético e conhecimento tradicional, a instituição e o tempo de competência para emissão de tais autorizações. $\mathrm{O} \mathrm{CNPq}$ emitiu 154 autorizações em 4 anos, o CGEN 147 em 10 anos, o IBAMA, 104 em 6 anos e o IPHAN, 19 em 2 anos (Figura 5).

Os dados acima demonstram a precariedade e a ineficiência do sistema de concessão de autorizações de acesso ao patrimônio genético, principalmente quando se trata de um país continental como o Brasil, detentor da maior biodiversidade do planeta. Quando se trata de acesso ao conhecimento tradicional associado, os números são ainda mais alarmantes, pois foram apenas 54 autorizações emitidas pelo CGEN e 19 pelo IPHAN, totalizando 73 autorizações em 10 anos, para um país também considerado megassociodiverso. Além disso, os números mostram também a dificuldade de empresas conseguirem tais autorizações para desenvolver produtos que poderão trazer lucro e benefícios para a sociedade como um todo. Foram apenas 56 autorizações em 10 anos.

Ao CGEN cabe, no momento, autorizar solicitações que envolvam os dois acessos simultaneamente: ao patrimônio genético com finalidade de bioprospecção e desenvolvimento tecnológico e ao conhecimento tradicional associado.

Pela análise da Tabela 1, fica evidente que o CGEN descentralizou as competências não só para diversos órgãos como para vários Ministérios. O que antes era da competência apenas do Ministério do Meio Ambiente, hoje está pulverizado pelos Ministérios da Ciência, Tec-

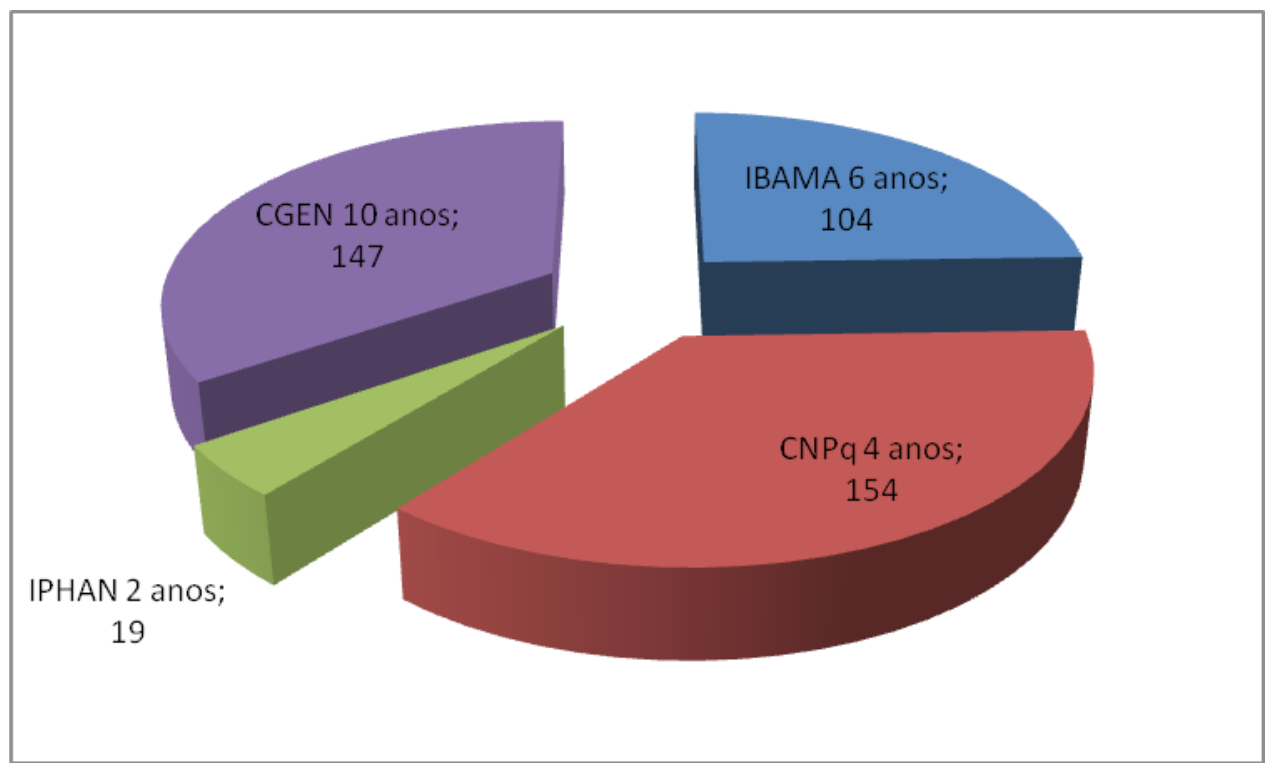

FIGURA 5 - Relação ente o número de autorizações, a instituição e o tempo de competência. FONTE: Godinho \& Mota (2013), a partir dos dados das Figuras 1 a 4.

\footnotetext{
${ }^{13}$ Entre 2007 e 2011, a receita líquida da Natura saltou de R 3 bilhões para R \$ 5,5 bilhões, os pedidos de produtos passaram de 9 milhões para 17 milhões ao ano e a participação das operações internacionais saiu de 4,4\% e chegou a 9\% (cf. Pesquisa FAPESP, edição n. 195, maio de 2012, p. 60).
} 
nologia e Inovação e Ministério da Cultura. Resta saber se tal divisão se mostrará benéfica ao objetivo que se propõe, uma vez que, para ser bem-sucedida, será necessária uma perfeita comunicação e tramitação das informações entre esses três Ministérios, além de paridade de conceitos e visões, que muitas das vezes não são verificadas.

TABELA 1 - Resumo das autorizações de acesso e coleta aos recursos genéticos e aos conhecimentos tradicionais associados.

\begin{tabular}{lc}
\hline \multicolumn{1}{c}{ Autorização } & Órgão Competente \\
\hline Coleta & ICMBio-MMA \\
\hline Acesso e remessa de componente & CNPq - MCTI \\
de patrimônio genético para fins & IBAMA - MMA \\
de pesquisa científica, sem acesso \\
ao conhecimento tradicional asso- \\
ciado.
\end{tabular}

Acesso e remessa de componente de patrimônio genético para fins de bioprospecção e desenvolvimento tecnológico, sem acesso ao conhecimento tradicional associado.

Acesso a conhecimento tradicio- IPHAN - Ministério da nal associado para fins de pesqui- Cultura

sa científica

Acesso a componente de patriCGEN - MMA mônio genético e conhecimento tradicional associado simultaneamente com finalidade de bioprospecção e desenvolvimento tecnológico

A Tabela 1 demonstra claramente que a instituição que desejar solicitar autorização de acesso e/ou remessa a qualquer dos órgãos credenciados e até mesmo ao CGEN precisa necessariamente saber o tipo de atividade que pretende desenvolver, se pesquisa científica, bioprospecção ou desenvolvimento tecnológico. Ocorre que a legislação apenas estabelece a definição de bioprospecção em seu artigo $7^{\circ}$, VII, deixando em aberto o que seria considerado pesquisa científica e desenvolvimento tecnológico. E ainda assim, na definição de bioprospecção não esclarece o que considera potencial de uso comercial, deixando mais uma vez às cegas as instituições interessadas em desenvolver tais atividades.

Todas essas indefinições exigiram mais uma vez a intervenção do CGEN, que, por meio da Orientação Téc- nica $n^{0} 6 / 2008$, esclarece que, para fins de aplicação do disposto na Medida Provisória 2.186-16/01, considera-se identificado o "potencial de uso comercial" de determinado componente do patrimônio genético no momento em que a atividade exploratória confirme a viabilidade de produção industrial ou comercial de um produto ou processo a partir de um atributo funcional desse componente. A intenção do CGEN é desonerar quem realiza esse tipo de pesquisa, verificando, muitas vezes, que não será possível desenvolver o produto industrialmente.

Para preencher a lacuna da definição de desenvolvimento tecnológico, o CGEN elaborou a Orientação Técnica $n^{\circ} 4 / 2004$, entendendo-o como o trabalho sistemático, decorrente do conhecimento existente, que visa à produção de inovações específicas, à elaboração ou à modificação de produtos ou processos existentes, com aplicação econômica. O conceito de pesquisa científica, por exclusão dos outros dois, fica considerado como sendo aquela que não visa diretamente ao desenvolvimento de produtos, apenas à geração de conhecimento científico.

Tais ações não isentam a Medida Provisória, conforme enfatizado por Mota (2009, p. 131), de críticas porque, apesar de estar em vigor desde 2001, não conseguiu estabelecer normas claras e eficazes de acesso ao patrimônio genético no país.

Com as mudanças relativas à descentralização do trabalho do CGEN, a fabricante de cosméticos Natura, até 2011, havia sido atendida em dez pedidos de exploração econômica de plantas. Antes, de acordo com Castro (2011, p. 1), a empresa havia recebido multas que totalizavam R \$ 21 milhões por uso de recursos genéticos sem autorização. Em 2012, o CGEN concedeu apenas à Natura 26 autorizações de acesso. O autor esclarece, no entanto, que, apesar dessas aprovações, a empresa ainda permanece cética em relação aos avanços no CGEN, pois considera que, enquanto não houver modificação na legislação, as medidas serão apenas paliativas.

\section{Conclusão}

Neste artigo, ficam evidentes vários problemas e conflitos ainda existentes e que precisam ser superados antes de compatibilizar as exigências das atividades de 
pesquisa científica com as determinações legais. Por gerarem insegurança jurídica, o CGEN tem tomado a iniciativa de esclarecer as dubiedades da MP 2.18616/2001 elaborando resoluções e orientações técnicas. Contudo, estamos diante de medidas paliativas, porque nos encontramos envoltos, metaforicamente, em uma colcha de retalhos de difícil entendimento, até mesmo para os estudiosos do assunto, quanto mais para os leigos em legislação: ambos gostariam de ter esclarecida qual a melhor e mais efetiva forma de acessar os recursos genéticos e os seus conhecimentos tradicionais associados para poder realizar suas pesquisas e transformá-los ou não em bens públicos e/ou privados da bioeconomia. Em um âmbito mais geral, todos gostariam que um tema de grande relevância como esse fosse disciplinado pelo poder legislativo por meio de uma legislação federal ordinária e não como vem sendo feito até o momento, onde apenas o poder executivo disciplina o assunto.

A estrutura organizacional do CGEN também é alvo de severas críticas, porque as representações de povos indígenas, comunidades tradicionais e quilombolas, bem como as organizações da sociedade civil, só podem acompanhar os debates nos fóruns de discussão como convidados e não possuem participação nos espaços decisórios propriamente ditos. A esses atores sociais foi

\section{Referências}

Azevedo, C. M. do A. A regulamentação do acesso aos recursos genéticos e aos conhecimentos tradicionais associados no Brasil. Biota Neotropica, 5(1), 1-9, 2005. Disponível em: $<$ http://www.biotaneotropica.org.br/v5n1/pt/abstract?point-of-view+BN001050/2005>.

Bensusan, N. Breve histórico da regulamentação do acesso aos recursos genéticos no Brasil. In: Lima, A.; Bensusan, N. (Orgs.). Quem cala consente? Subsídios para proteção aos conhecimentos tradicionais. São Paulo: Instituto Socioambiental, 2003. p. 9-16.

Brasil. Constituição da República Federativa do Brasil, de 5 de outubro de 1988. Organização do texto: Guilherme Peña de Moraes. 4. ed. Rio de Janeiro: Lumen Juris, 2006.

. Medida Provisória 2.186-16, de 23 de agosto de 2001a. Regulamenta o inciso II do $\S 1^{\circ}$ e o $\S 4^{\circ}$ do art. 225 da Constituição, os arts. $1^{\circ}, 8^{\circ}$, alínea “j”, 10, alínea “c", 15 e outorgado o direito de participar de forma figurativa e não efetiva.

A análise dos resultados mostra claramente que o CGEN descentralizou as competências não só para diversos órgãos, como também para vários Ministérios. $\mathrm{O}$ que antes era da competência exclusiva do Ministério do Meio Ambiente, hoje está pulverizado pelos Ministérios da Ciência e Tecnologia e da Cultura. Tal divisão demonstra o propósito do CGEN de se tornar um órgão recursal, uma vez que a Medida Provisória também não estabeleceu tal previsão. Esta repartição, embora tenha certamente o objetivo de oferecer maior celeridade ao processo de emissão de licenças, exige uma perfeita comunicação e tramitação das informações entre os ministérios envolvidos, além de paridade de conceitos e visões, que deverão ir além dos conflitos de interesses muitas vezes evidenciados.

\section{Agradecimentos}

O primeiro autor agradece à Coordenação de Aperfeiçoamento de Pessoal de Nível Superior-CAPES - pelo financiamento da presente pesquisa.

16, alíneas 3 e 4 da Convenção sobre Diversidade Biológica, dispõe sobre o acesso ao patrimônio genético, a proteção e o acesso ao conhecimento tradicional associado, a repartição de benefícios e o acesso à tecnologia e transferência de tecnologia para sua conservação e utilização, e dá outras providências. Brasília: DOU de 24/08 2001.

. Decreto $n^{\circ} .3 .945$ de 28 de setembro de 2001b. Define a composição do Conselho de Gestão do Patrimônio Genético e estabelece as normas para o seu funcionamento, mediante a regulamentação dos arts. 10,11, 12, 14, 15, 16, 18 e 19 da Medida Provisória n ${ }^{\circ}$. 2.186-16, de 23 de agosto de 2001, que dispõe sobre o acesso ao patrimônio genético, a proteção e o acesso ao conhecimento tradicional associado, a repartição de benefícios e o acesso à tecnologia e transferência de tecnologia para sua conservação e utilização, e dá outras providências. Brasília: DOU de 3/10/2001. 
. Decreto $n^{\circ} .4 .946$ de 31 de dezembro de 2003. Altera, revoga e acrescenta dispositivos ao Decreto $n^{\circ} 3.945$, de 28 de setembro de 2001, que regulamenta a Medida Provisória

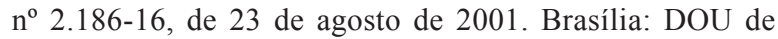
$5 / 01 / 2004$.

Carvalho, I. de. CNPq agiliza processos de acesso a recursos da biodiversidade. Revista Ecológica [S.I.]: Editora Biodiversidade, jan. 2012. Disponível em: <http://revistaecologica.com/ index.php?option $=$ com_content $\&$ view $=$ article $\& i d=3062 \% 3 \mathrm{~A}$ cnpq-agiliza-processos-de-acesso-a-recursos-da-biodiversidad e\&catid $=343 \% 3$ Abiodiversidade $>$.

Castilho, E. W. V. de. Parâmetros para o regime jurídico sui generis de proteção ao conhecimento tradicional associado a recursos biológicos e genéticos. In: Mezzaroba, O. (Org.). Humanismo latino e Estado no Brasil. Florianópolis: Fundação Boiteux, Fondazione Casamarca, 2003. p. 453-472.

Castro, F. de. Avanços possíveis. Agência FAPESP. Agência de notícias da Fundação de Amparo à Pesquisa de São Paulo. 2011. Disponível em: <http://www.agencia.fapesp.br/14317>.

CGEN - Conselho de Gestão do Patrimônio Genético. Deliberação $n^{\circ}$ 40, de 24 de setembro de 2003a. Brasília: DOU de 20/10/2003.

. Orientação Técnica $n^{\circ} 1$, de 24 de setembro de $2003 b$. Brasília: DOU de 24/10/2003.

. Orientação Técnica $n^{\circ}$ 4, de 27 de maio de 2004. Brasília: DOU de 17/06/2004.

. Resolução $n^{\circ}$ 21, de 31 de agosto de 2006. Brasília: DOU de $12 / 09 / 2006$.

. Resolução no 29, de 06 de novembro de 2007. Brasília: DOU de 27/12/2007.

. Orientação Técnica $n^{\circ}$ 6, de 28 de agosto de 2008. Brasília: DOU de 29/09/2008.

. Deliberação $n^{\circ}$ 246, de 27 de agosto de 2009. Brasília: DOU de 16/09/2009.

. Deliberação $n^{\circ} 268$, de 9 de dezembro de 2010. Brasília: DOU de 5/09/2011.

Deliberação $n^{\circ}$ 279, de 20 de setembro de 2011. Brasília: DOU de 09/11/2011.
Conferência das Nações Unidas sobre Meio Ambiente e Desenvolvimento. Convenção sobre Diversidade Biológica. 1992. Disponível em: <http://www.onu-brasil.org.br/doc_cdb.php>.

Conselho Nacional de Desenvolvimento Científico e Tecnológico (CNPq). Resolução Normativa $n^{\circ} 3$, de 10 de fevereiro de 2012. Brasília: DOU de 11/02/2012.

Denzin, N. K.; Lincoln, Y. S. Introduction: Entering the field of qualitative research. In: Handbook of Qualitative Research. Thousand Oaks, CA: Sage, 1994. p. 1-17.

Godinho, R. de S.; Machado, C. J. S. Avanços e percalços na elaboração da legislação nacional sobre acesso a recursos genéticos e aos conhecimentos tradicionais associados. Revista Desenvolvimento e Meio Ambiente, 24, 83-99, 2011.

Instituto Brasileiro do Meio Ambiente e dos Recursos Naturais Renováveis - IBAMA. Instrução Normativa $n^{\circ} 154$ de 01 de março de 2007. Brasília: DOU de 2/03/2007.

Kishi, S. A. S. Tutela jurídica do acesso à biodiversidade no Brasil. Meio Ambiente - Grandes Eventos, Brasília: ESMPU, 1, 167-179, 2004.

Machado, C. J. S.; Godinho, R. de S. Dinâmica e características do processo brasileiro de regulação do acesso à diversidade biológica e aos conhecimentos tradicionais associados. Revista de Informação Legislativa, 191, 99-121, jul.-set. 2011.

Mota, M. J. P. da. Direitos intelectuais coletivos e função social da propriedade intelectual: os conhecimentos tradicionais associados à biodiversidade. In: (Coord.). Função social do Direito Ambiental. Rio de Janeiro: Elsevier, 2009. p. 90-153.

Szpilman, M. Biodiversidade - As nações mais ricas em diversidade do planeta. Informativo Instituto Ecológico Aqualung, 20, 1-2, julho/agosto 1998. Disponível em: $<$ http://www.institutoaqualung.com.br/info_biodiversidade23.html $>$.

Tárrega, M. C. V. B.; Pérez, H. L. A. A tutela jurídica da biodiversidade: a influência da Convenção sobre a Diversidade Biológica no sistema internacional de patentes. In:

(Org.). Direito Ambiental e desenvolvimento sustentável. São Paulo: RCS Editora, 2007. p. 1-16.

Vasconcellos, C. Uso da biodiversidade: ainda em busca de agilidade. Jornal da Ciência, Sociedade Brasileira para o Progresso da Ciência - SBPC. 2012. Disponível em: <http:// www.jornaldaciencia.org.br/Detalhe.jsp?id=81044>. 